\title{
Surface Tension and Fluid Flow Driven Self Assembly of Ordered ZnO Nanorod Films for High-Performance Field Effect Transistor
}

\author{
Baoquan Sun and Henning Sirringhaus* \\ Cavendish Laboratory, University of Cambridge, JJ Thomson Avenue, Cambridge, CB3 \\ 0HE United Kingdom
}

\section{S1 Calculating surface and interface tension}

The particle-air surface tensions $\gamma_{\mathrm{p} / \mathrm{a}}$ for different ligands are estimated from the measured water contact angles of films of nanoparticles (Fig. 1). To do this we make use of a theoretical model ${ }^{1,2}$ for estimating the liquid-particle (water/ligand) interfacial tension $\gamma_{1 / \mathrm{p}}$ from the surface tension of the particles $\gamma_{\mathrm{p} / \mathrm{a}}$ and the liquid $\gamma_{1 / \mathrm{a}}$ :

$$
\gamma_{1 / p}=\gamma_{\mathrm{p} / \mathrm{a}}+\gamma_{1 / \mathrm{a}}-2 \Phi\left(\gamma_{\mathrm{p} / \mathrm{a}} \gamma_{1 / \mathrm{a}}\right)^{1 / 2}
$$

By using equation (1) and Young's equation, $\gamma_{\mathrm{p} / \mathrm{a}}=\gamma_{1 / \mathrm{a}} \cos \theta+\gamma_{1 / \mathrm{p}}, \gamma_{1 / \mathrm{p}}$ can be eliminated and using the known liquid-air surface tension $\gamma_{1 / \mathrm{a}}$ for water $\gamma_{\mathrm{p} / \mathrm{a}}$ can be expressed as:

$$
\gamma_{\mathrm{p} / \mathrm{a}}=\gamma_{1 / \mathrm{a}}(1+\cos \theta)^{2} /\left(4 \Phi^{2}\right)
$$

The parameter $\Phi$ can be shown to be determined by the molar volume of the particle $V_{p}$ and liquid $\mathrm{V}_{1}$ :

$$
\Phi=4\left(\mathrm{~V}_{\mathrm{p}} \mathrm{V}_{\mathrm{l}}\right)^{1 / 3} /\left(\mathrm{V}_{\mathrm{p}}^{1 / 3}+\mathrm{V}_{\mathrm{l}}^{1 / 3}\right)^{2}
$$

The parameter $\Phi$ can be obtained if the particle molar volume $V_{p}$ values is estimated from the corresponding ligand alkylamine molar volume because the effective interface is that between the liquid and the ligand molecules on the surface. ${ }^{1}$ The parameter 
$\Phi_{\text {water/BUTA }}$ value of 0.924 is obtained according equation (3) to determine interfacial energy between water and BUTA-ZnO. In the same way, $\Phi_{\text {water/OCTA value is } 0.875 \text { for }}$ that between water and OCTA-ZnO. We can estimate $\gamma_{\mathrm{p} / \mathrm{a}}$ for different ligands using Equation 2 and the known surface tension of $71.98 \mathrm{~mJ} / \mathrm{m}^{2}$ of water. We find that there is a difference of $6.16 \mathrm{~mJ} / \mathrm{m}^{2}$ between the surface tension of BUTA- $\mathrm{ZnO}\left(\gamma_{\mathrm{p} / \mathrm{a}}^{\text {BUTA }}=33.94\right.$ $\left.\mathrm{mJ} / \mathrm{m}^{2}\right)$ and that of OCTA-ZnO $\left(\gamma_{\mathrm{p} / \mathrm{a}}{ }^{\text {OCTA }}=27.78 \mathrm{~mJ} / \mathrm{m}^{2}\right)$.

Using these values for the surface tension of the ligand modified nanorods we then can apply Equation 1 again to the case of the nanorod solution in chloroform/methanol and calculate the interface tension between the nanorods and the solvent using the appropriate values of $\Phi$ for chloroform/methanol as the solvent. Here the liquid is chloroform/methanol and its surface energy $\gamma_{1 / \mathrm{a}}$ is $26.74 \mathrm{~mJ} / \mathrm{m}^{2}$ which is in between the surface energy of methanol $\gamma_{\text {methanol } / \text { air }}=22.98 \mathrm{~mJ} / \mathrm{m}^{2}$ and that of chloroform $\gamma_{\text {chloroform } / \text { air }}=$ $28.02 \mathrm{~mJ} / \mathrm{m}^{2}$ as determined by the ring method. We have not been able to observe surfactant action of the alkylamine molecule in the chloroform/methanol solvent, i.e., no lowering of the solvent surface tension compared to that of the pure solvent was observed when alkylamine molecules were dissolved at a concentration of $1.5 \%, \mathrm{~V} / \mathrm{V}$ in chloroform/methanol. The interfacial free energy value for the chloroform/methanolBUTA-ZnO interface is $\gamma_{\mathrm{p} / \mathrm{l}}^{\text {BUTA }}=0.670 \mathrm{~mJ} / \mathrm{m}^{2}$ based on the parameter $\Phi_{\text {solvent } / \mathrm{BUTA}}=$ 0.996. Similarly, the interfacial free energy from chloroform/methanol-OCTA-ZnO $\left(\gamma_{\mathrm{p} / 1}{ }^{\text {oct }}\right)$ is $\gamma_{\mathrm{p} / \mathrm{l}}{ }^{\mathrm{OCTA}}=1.21 \mathrm{~mJ} / \mathrm{m}^{2}$ for $\Phi_{\text {solvent/OCTA }}=0.978$.

\section{S2 Calculating change of surface potential}

As discussed in the paper the self-assembly behavior is determined by the segregation and nucleation of the nanorods to the liquid/air interface. The driving force for nanorod segregation to the surface can be estimated by calculating the change of surface potential $\Delta \mu$ when a nanorods segregates from the bulk of the liquid to the surface. For the purpose of this estimate we assume that the nanorods on the surface are oriented vertical to the surface due to vertical liquid flowing ${ }^{3-6}$, and that a length $\mathrm{H}$ of the long axis of the nanorods (total length L, radius $\mathrm{R}$ ) is protruding out of the surface and is in contact with 
air (see Scheme 1(g)). There are three contributions to the surface potential of a nanorod on the surface measured with respect to that of the surface of the pure liquid ${ }^{7}$.

a) Surface potential of nanorod/air interface:

$$
\mu_{\mathrm{p} / \mathrm{a}}=\gamma_{\mathrm{p} / \mathrm{a}} \cdot\left(\pi \mathrm{R}^{2}+2 \pi \mathrm{RH}\right)
$$

b) Surface potential of nanorod/liquid interface:

$$
\mu_{\mathrm{p} / l}=\gamma_{\mathrm{p} / l} \cdot\left[\pi \mathrm{R}^{2}+2 \pi \mathrm{R}(\mathrm{L}-\mathrm{H})\right]
$$

c) Negative surface potential due to the portion of the liquid/air interface that has been displaced by the nanorods:

$$
\mu_{1 / a}=-\gamma_{1 / a} \cdot \pi R^{2}
$$

The total surface potential can be written:

$$
\mu_{\text {total }}=\pi R^{2}\left(\gamma_{\mathrm{p} / \mathrm{a}}+\gamma_{\mathrm{p} / 1}-\gamma_{1 / \mathrm{a}}\right)+2 \gamma_{\mathrm{p} / /} \pi \mathrm{RL}+\mathrm{H} \cdot 2 \pi \mathrm{R}\left(\gamma_{\mathrm{p} / \mathrm{a}}-\gamma_{\mathrm{p} / \mathrm{l}}\right)
$$

The liquid is chloroform/methanol in this case. The surface potential $\mu_{\text {total }}$ will be a minimum value $\mu_{\min }$ if $\mathrm{H}=0$, and only the end surface of the nanoparticle is exposed to air since $\left(\gamma_{\mathrm{p} / \mathrm{a}}-\gamma_{\mathrm{p} / 1}\right)>0$ :

$$
\mu_{\min }=\pi R^{2}\left(\gamma_{\mathrm{p} / \mathrm{a}}+\gamma_{\mathrm{p} / 1}-\gamma_{1 / \mathrm{a}}\right)+2 \gamma_{\mathrm{p} / /} \pi \mathrm{RL}=\gamma_{1 / \mathrm{a}}\left[\pi \mathrm{R}^{2}(\mathrm{x}+\mathrm{y}-1)+2 \mathrm{y} \pi \mathrm{RL}\right]
$$

with $\mathrm{x}=\gamma_{\mathrm{p} / \mathrm{a}} / \gamma_{1 / \mathrm{a}}$ and $\mathrm{y}=\gamma_{\mathrm{p} / 1} / \gamma_{1 / \mathrm{a}}$. In comparison, the surface potential $\mu_{\mathrm{liquid}}$ of a nanorod totally immersed in liquid is

$$
\mu_{\text {liquid }}=\gamma_{\mathrm{p} / l} \cdot\left(2 \pi \mathrm{R}^{2}+2 \pi \mathrm{RL}\right)
$$


The potential barrier for nanoparticles to segregate from the bulk liquid to the surface $\Delta \mu_{1}$ is

$$
\Delta \mu_{1}=\mu_{\text {liquid }} \mu_{\min }=\pi R^{2}\left(\gamma_{\mathrm{p} / 1}-\gamma_{\mathrm{p} / \mathrm{a}}+\gamma_{1 / \mathrm{a}}\right)=\pi \mathrm{R}^{2} \gamma_{1 / \mathrm{a}}(\mathrm{y}-\mathrm{x}+1)
$$

Here, the average values for $\mathrm{ZnO}$ nanorods are $\mathrm{R}=5.5 \mathrm{~nm}$ and $\mathrm{L}=92 \mathrm{~nm}$ and the difference in size due to nanorods ligands is neglected. In the BUTA-ZnO case, since $\mathrm{x}=1.269$ and $\mathrm{y}=0.0251, \Delta \mu_{1}{ }^{\mathrm{BUTA}}=-0.244 \pi \mathrm{R}^{2} \gamma_{1 / \mathrm{a}}$ is obtained from Equation 10 respectively, i.e. there is no driving force for the particle to expose a portion of its surface to air. However, in the case of OCTA-ZnO, $\Delta \mu_{1}{ }^{\text {OCTA }}=0.063 \pi \mathrm{R}^{2} \gamma_{1 / \mathrm{a}}$ can be calculated using $\mathrm{x}=0.955$ and $\mathrm{y}=0.0433$, and this constitutes a potential for trapping the particle at the surface.

\section{References}

1. Girifalco, L. A.; Good, R. J. J. Phys. Chem. 1957, 61, 904-909.

2. Good, R. J.; Girifalco, L. A. J. Phys. Chem. 1960, 64, 561-565.

3. Huang, Y.; Duan, X. F.; Wei, Q. Q.; Lieber, C. M. Science 2001, 291, 630-633.

4. Messer, B.; Song, J. H.; Yang, P. D. J. Am. Chem. Soc. 2006, 122, 10232-10233.

5. Stone, H. A.; Kim, S. AICHE J. 2001, 47, 1250-1254.

6. Yang, P. D. Nature 2003, 425, 243-244.

7. Pieranski, P. Phy. Rev. Lett. 1980, 45, 569-572. 